\title{
Changes in Global Blocking Character in Recent Decades
}

\author{
Anthony R. Lupo 1,*(D), Andrew D. Jensen ${ }^{2}$, Igor I. Mokhov ${ }^{3,4}$, Alexander V. Timazhev ${ }^{3}$, \\ Timothy Eichler ${ }^{5}$ and Bahtiyar Efe ${ }^{1,6}$ (D) \\ 1 Atmospheric Science Program, School of Natural Resources, University of Missouri, \\ Columbia, MO 65211, USA \\ 2 Department of Mathematics and Meteorology, Northland College, Ashland, WI 54806, USA; \\ ajensen@northland.edu \\ 3 A.M. Obukhov Institute of Atmospheric Physics, Russian Academy of Science, 3 Pyzhevsky, \\ Moscow 119017, Russia; mokhov@ifaran.ru (I.I.M.); timazhev@ifaran.ru (A.V.T.) \\ 4 Faculty of Physics, Lomonosov State University, Moscow 119991, Russia \\ 5 Department of Geosciences, University of Arkansas, Fayetteville, AR 72701, USA; tpeichle@uark.edu \\ 6 Department of Meteorology, Istanbul Technical University, Istanbul, Maslak 34467, Turkey; efeba@itu.edu.tr \\ * Correspondence: lupoa@missouri.edu; Tel.: +1-573-884-1638
}

Received: 3 February 2019; Accepted: 18 February 2019; Published: 21 February 2019

check for updates

\begin{abstract}
A global blocking climatology published by this group for events that occurred during the late 20th century examined a comprehensive list of characteristics that included block intensity (BI). In addition to confirming the results of other published climatologies, they found that Northern Hemisphere (NH) blocking events (1968-1998) were stronger than Southern Hemisphere (SH) blocks and winter events are stronger than summer events in both hemispheres. This work also examined the interannual variability of blocking as related to El Niño and Southern Oscillation (ENSO). Since the late 20th century, there is evidence that the occurrence of blocking has increased globally. A comparison of blocking characteristics since 1998 (1998-2018 NH; 2000-2018 SH) shows that the number of blocking events and their duration have increased significantly in both hemispheres. The blocking BI has decreased by about six percent in the $\mathrm{NH}$, but there was little change in the BI for the $\mathrm{SH}$ events. Additionally, there is little or no change in the primary genesis regions of blocking. An examination of variability related to ENSO reveals that the NH interannual-scale variations found in the earlier work has reversed in the early 21st century. This could either be the result of interdecadal variability or a change in the climate. Interdecadal variations are examined as well.
\end{abstract}

Keywords: blocking; ENSO; climate change; interdecadal variability; Pacific Decadal Oscillation; North Atlantic Oscillation; Atlantic Multidecadal Oscillation

\section{Introduction}

Many recent studies have examined the climatological behavior of blocking in both the Northern $(\mathrm{NH})$ and Southern Hemispheres $(\mathrm{SH})$ in the later part of the 20th century using a variety of blocking criteria [1-9]. Among the common findings in the NH are that blocking events are more frequent and persistent during the cold season, and that there are three preferred blocking sectors over the Pacific and Atlantic ocean regions and the Eurasian region at the end of the NH storm tracks $[1,10]$. In the SH, the Pacific Ocean region is the predominant sector for blocking, with occurrences similar to those of the NH Pacific [1]. The work of Burkhardt et al. [11] demonstrated that in the SH, the dynamic synoptic and planetary interactions between upstream cyclones and large-scale ridges are weaker especially within the Atlantic and Indian Ocean sectors. This accounts for the relative dearth of blocking that occurs in the $\mathrm{SH}$ as a whole. 
The studies of $[1,5]$ and [7] examine a long list of blocking characteristics including the number of events, days, duration, intensity, and location at onset. Most other climatologies use only the occurrence, day, and/or durations of blocking events. These studies found that $\mathrm{NH}$ blocking was more intense during the boreal cold season than during the warm season using the blocking intensity (BI) index of [1]. Only [1] has examined the intensity of SH blocking and found that the seasonal variation in $\mathrm{BI}$ is the same as that in the $\mathrm{NH}$ even though SH blocking is weaker overall.

Many studies have suggested that the occurrence of blocking varies interannually in association with El Niño and Southern Oscillation (ENSO) showing inconsistent results. The work of [1] showed that in the NH blocking occurred more often during La Niña years and was more persistent and intense. This association was found in each region and season. The climatology of [1] examined events from mid-1968 to mid-1998. Then [5] using a 55-year climatology (1948-2002) suggested that there was little ENSO variability except in NH block intensity. In [5], blocking was more intense during La Niña years. In the SH, [1] demonstrated than blocking occurred more frequently during El Niño years, and also these events were more persistent and stronger. A 53-year SH study (1958-2010) [12] of winter events also showed blocking was more frequent and associated with more blocking days during El Niño years. However, it should be noted here that [12] considered blocking events to persist for at least three days rather than the five days found in most studies.

Many of these studies also suggested that there were long-term trends or interdecadal variability in block occurrences. In the SH [1] demonstrated that there was a strong decrease in the occurrence and duration of blocking during the late 20th century, and this trend was consistent with that of other researchers (e.g., [13]). However, the longer-term climatology of [12] found no statistically significant trend in the SH overall, even though there were regional increases across most of the SH. In the NH [1] and [5] show mixed results in the long-term trend of $\mathrm{NH}$ blocking occurrence depending on the region and season. Then, [5] showed that there were interdecadal variations in NH blocking occurrences related to such teleconnections as the North Atlantic Oscillation (NAO) or the West Pacific (WP) pattern (see [14]).

Some [6-9] have examined the occurrence of NH blocking into the early part of the 21st century. Firstly, [6] implied that the number of NH Atlantic Region events is increasing, but that the period 1970-1999 was likely a period of low blocking occurrence. Also, [15] reviewed several studies and showed that the Atlantic Region near Greenland has experienced more blocking into the 21st century. These results are corroborated by [7], who used three different blocking indexes showing an increase in the occurrence of $\mathrm{NH}$-wide blocking during the early 21st century, but that the period covered in [1] represented a relative minimum in the occurrence of blocking. Others, such as [8] and [9], suggest that the primary location for Atlantic Region block occurrences has changed in recent decades into the early 21st century in association with arctic amplification. For an example of arctic amplification see Barnes et al. [16]. In the SH, [12] found that there were increases in blocking frequency within the Pacific Region (western and eastern), but a decrease in the central Pacific. This study did not examine interdecadal variability, and there is additional observational evidence to suggest that there has been an increase in the occurrence of blocking since 2000 in the Atlantic and Indian sectors as well.

Most of the blocking indexes cited above are one-dimensional (1D), meaning that only the longitude of the block center is located in order to count occurrence frequency. In 2006, [17] extended a commonly used 1D blocking index to two dimensions (2D), which means that the latitude and longitude are identified in order to count occurrence frequency. This study examined blocking in the Euro-Atlantic sector and found that the correlation between the 2D blocking index and Atlantic Region teleconnections corresponded to previously published correlations between $1 \mathrm{D}$ blocking indexes and these teleconnections. Then [18] used the [17] blocking index to examine the interannual variability and trends in NH blocking from 1951 to 2010. They found the following results; a) extended the BI of [1] to two dimensions, $b$ ) identified the primary blocking regions found by $1 D$ blocking indexes using the [17] 2D index, c) identified strong interannual variability in the primary NH blocking regions, and d) found a strong increase in blocking frequency and intensity over the Atlantic region. 
Additionally, [18] identified a shift toward more blocking events into the central Pacific and fewer events over Northern Russia.

Other studies, (e.g., [19]) have used this 2D blocking index to relate regional blocking to local climate. Another type of 2D index was developed by [20], which is the area integral of the local gradient representing the region of the blocking system (center and surroundings). This quantity will have units of energy $x$ time and can be summed up through the lifecycle of the blocking event (and then summed up by region and season). They [20] referred to this index as an integral action or intensity index. In the NH, [20] used this index over the same time period as [1]. This work showed the similar results as [1] for block occurrences and intensity in the $\mathrm{NH}$ over different seasons and regions, as well as with respect to interannual variations such as ENSO.

Many studies have also examined projections for the future occurrence of blocking (e.g., [7,15,21-24]. Some of these studies projected that the occurrence of blocking may increase in a warmer world [21], while increasing their duration but weakening. Others have suggested either a decrease [22,23] or little change $[7,24]$ in future blocking occurrences far into the 21st century. However, the review published by [15] found that in the balance, NH blocking would become less frequent and persistent, but still play a critical role in the occurrence of extreme warm or cold events as well as drought.

The goal of this work is to make a comprehensive comparison of the global occurrence of blocking since the end of the 20th century to the climatologies of [1] and [5] (1 July 1998-30 June 2018-NH; 1 January 2000-31 December 2018-SH). This work will examine the more comprehensive list of blocking characteristics that the earlier studies examined including BI. This study will also determine if there has been any changes in the trends or interannual variability of any of these variables, as well as the possibility of interdecadal variability in these variables and compare these to [1] and [5]. This work will use primarily the National Centers of Environmental Prediction/National Center for Atmospheric Research (NCEP/NCAR) reanalyses. This study is unique in that this research group is the only one that defines and examines BI across the globe. BI has been shown also to be related to dynamic quantities such as the $500 \mathrm{hPa}$ height gradients [1], enstrophy, and entropy (e.g., Kolmogorov-Saini Entropy [25]). Additionally, this work will compare our results for SH blocking into the 21st century to those of [12] where appropriate.

\section{Data and Methods}

\subsection{Data}

The data used here were the NCEP/NCAR reanalyses $500 \mathrm{hPa}$ height fields on a $2.5^{\circ}$ latitude by $2.5^{\circ}$ longitude gridded dataset available at 6-h intervals [26,27]. The 1200 UTC data was used primarily in the calculation of intensity since these data tend to include the most number of observational data. This study also used data archived in [28], which contains a list of all blocking events since the beginning of the [1] study. The extended period of study here in the NH is from 1 July 1998 to 30 June 2018 (20 additional seasons), while for the SH the period included that from 1 January 2000 to 31 December 2018 (19 additional seasons). These reanalyses were used by [1] and the rationale for the starting dates chosen here is that these dates were the termination dates of the [1] study. The ending dates chosen here correspond to the seasonality defined in [1]. Thus, Section 3 will examine recent blocking activity since approximately the end of the 20th century.

In order to facilitate comparisons to [1] and [5], the blocking seasons (regions) follow the blocking year (geographic boundaries) established by [1]. In particular, the boreal (austral) summer, fall, winter, and spring in the NH (SH) are July-September (January-March), October-December (April-June), January-March (July-September), and April-June (October-December), respectively. In the NH and $\mathrm{SH}$ the Atlantic Region (ATL) is defined as $80^{\circ} \mathrm{W}$ to $40^{\circ} \mathrm{E}$ and $60^{\circ} \mathrm{W}$ to $30^{\circ} \mathrm{E}$, respectively. The Pacific Region is defined as $140^{\circ} \mathrm{E}-100^{\circ} \mathrm{W}$ and $130^{\circ} \mathrm{E}$ to $60^{\circ} \mathrm{W}$ for the $\mathrm{NH}$ and $\mathrm{SH}$, respectively. In the $\mathrm{NH}$ the Continental Region (CON) encompasses $100^{\circ} \mathrm{W}$ to $80^{\circ} \mathrm{W}$ and $40^{\circ} \mathrm{E}$ to $140^{\circ} \mathrm{E}$, while in the $\mathrm{SH}$ the Indian Ocean Region (IND) is defined as $30^{\circ} \mathrm{E}$ to $130^{\circ} \mathrm{E}$. 


\subsection{Methodology}

The blocking criterion and BI used here were established by [1], and references therein. The definition for ENSO used here is described in [29] and references therein and a short description is given here. The Japanese Meteorological Agency (JMA) ENSO index is available through the Center for Ocean and Atmospheric Prediction Studies (COAPS) from 1868 to present [30]. The JMA classifies ENSO phases using SST within the bounded region of $4^{\circ} \mathrm{S}$ to $4^{\circ} \mathrm{N}, 150^{\circ} \mathrm{W}$ to $90^{\circ} \mathrm{W}$, and defines the inception of an ENSO year as 1 October, and its conclusion on 30 September of the next year. This index is widely used in other published works (see [25] and references therein), and a list of years is given in (Table 1). Also, [31] found that while the JMA index is more sensitive to La Niña events than other definitions, it is less sensitive than other indices to El Niño events.

Table 1. List of ENSO years used here. The years below are taken from [30].

\begin{tabular}{lll}
\hline El Niño & Neutral & La Niña \\
\hline 1969 & 1968 & 1967 \\
1972 & $1977-1981$ & $1970-1971$ \\
1976 & $1983-1985$ & $1973-1975$ \\
1982 & $1989-1990$ & 1988 \\
$1986-1987$ & $1992-1996$ & $1998-1999$ \\
1991 & $2000-2001$ & 2007 \\
1997 & $2003-2005$ & 2010 \\
2002 & 2008 & 2017 \\
2006 & $2011-2013$ & \\
2009 & 2016 & \\
$2014-2015$ & & \\
\hline
\end{tabular}

The Pacific Decadal Oscillation (PDO) positive and negative modes are catalogued also by the Center for Ocean-Atmospheric Prediction Studies (COAPS). The most important impact of the PDO is the interaction with ENSO during certain phases, which creates an either an enhanced effect on temperatures and precipitation variability over the central USA (e.g., [29,32-34]). The characteristics of these modes are less pronounced than those of ENSO due to the 50- to 70-year cycle of PDO [35,36]. The positive phase of the PDO is recognized as the period from 1977-1998, and the negative phases are recognized as the years 1947-1976 and 1999-2018.

The North Atlantic Oscillation (NAO) (e.g., [5,14]) is a north-south pressure oscillation in the North Atlantic whose fundamental dynamics are similar to that of the Pacific North American (PNA) pattern (e.g., [37-39]) or may be the regional expression of vacillation in the NH flow overall (e.g., [25]). It is well known that the time series of the daily or monthly NAO index values possess interannual (e.g., [5,40,41]) or interdecadal (e.g., [42,43]) modes. The decadal epochs for the NAO used here will be negative for the periods 1951-1972 and 1996-2010, while the positive epochs were 1972-1995 and 2011-2018. These were derived by examining the three-month running mean NAO index available from [44], and the earlier transitions agree with the published dates suggested in [42]. Additionally, studies such as [38] and [39] (and references) therein examined the occurrence of blocking in relation to the NAO from a climatological and theoretical point of view.

The Atlantic Multidecadal Oscillation (AMO), similar to the PDO, is a multidecadal basin-wide mode identified in the North Atlantic Region sea surface temperatures (e.g., [45-47]) and which has an impact on weather and climate of the Atlantic Region [45] and in other parts of the globe [47]. This phenomenon is quasi-periodic, usually identified as $60-90$ years, or about 70 years. The decadal epochs identified for AMO Index are taken to be defined as the cold phase (negative) from the early to mid-1960s to the mid- to late 1990s and the warm phase (positive) from the mid-1990s to the present. Many studies (e.g., [45]) label the cold phase as ending in 1995, while others use a later date such as 1998 (e.g., [46]). Here we will use the former date for the discussion of the AMO results, as the results 
in association with the latter date would be very similar to the results of Section 3. The blocking data will be stratified then by ENSO phase within each phase of the PDO, NAO, and AMO.

\section{Climatology of Blocking in the Early 21st Century}

\subsection{The Northern Hemisphere}

The most noteworthy character of blocking at the start of the 21st century (Table 2) is the increases in the occurrence, number of blocking days, and durations. In all regions and seasons, the increases and mean number of days are statistically significant at the 95\% confidence level, using the Z-score test for means [48]. The Atlantic Region showed the weakest increases, which is consistent with the results of [7]. The large increase in the occurrence and days within Pacific Region Blocking is consistent with the results of [29] who examined boreal spring and summer blocking in this region. Also, [49] and [50] showed a large increase in blocking occurrence for the Eastern Europe and Western Russia region for the boreal spring and summer as well. Additionally, [18] and [38] using the 2D index found an increase in blocking over the Atlantic sector. The former examined all seasons and the latter examined the cold season. Lastly, [5] found $1514 \mathrm{NH}$ blocking events in their 55-year blocking climatology (the late 20th century and very early 21st century), and here there were 1509 events over a 50-year period. Thus, there were approximately $9 \%$ more blocking events found here compared to [5], and this issue will be examined in Section 4.

Table 2. Character of NH blocking events per year as a function of region and season for all characteristics since the study of [1], and percent change in the value as compared to [1]. Bold values are statistically significant at the $90 \%$ confidence level and those with a $\left(^{*}\right)$ are statistically significant at the $95 \%$ confidence level or higher.

\begin{tabular}{|c|c|c|c|c|}
\hline Region & Occurrence & Duration & Days & Intensity \\
\hline Atlantic (ATL) & $16.0 /+25.0$ * & $10.5 /+11.7$ & $167.4 /+54.7$ * & $3.20 /-7.5$ * \\
\hline Pacific (PAC) & $11.9 /+80.3$ * & $9.5 /+25.0 *$ & $112.9 /+124.5$ * & $3.19 /-1.0$ \\
\hline Continental (CON) & $10.2 /+85.5$ * & $9.0 /+11.1$ & $91.2 /+105.4 *$ & $2.49 /-5.7$ * \\
\hline Total & $38.1 /+58.1$ * & $9.5 /+11.8$ & $360.4 /+70.6$ * & $3.03 /-5.9$ * \\
\hline Season & Occurrence & Duration & Days & Intensity \\
\hline Summer (Su) & $8.1 /+55.8 *$ & $10.1 /+31.2 *$ & $81.2 /+103.0 *$ & $2.32 /+4.5$ \\
\hline Fall $(\mathrm{F})$ & $8.5 /+57.4$ * & $9.6 /+18.5$ & $81.9 /+85.7$ * & $3.43 /-6.5$ * \\
\hline Winter (W) & $10.2 /+43.7^{*}$ & $9.7 /+9.0$ & $98.6 /+63.5$ * & $3.71 /-7.3$ * \\
\hline Spring (Sp) & $11.4 /+56.2 *$ & $9.7 /+22.8 *$ & $110.2 /+91.3 *$ & $2.65 /-2.9$ \\
\hline
\end{tabular}

The duration of blocking events was shown to increase, but the increases were not statistically significant across all regions. Only the Pacific Region showed statistically significant increases in duration. An examination by season shows that only the boreal winter blocking events were more persistent, but not at a statistically significant level. This insignificant increase during the winter in the Atlantic is different from those studies that found decreases in the duration of blocking using the 2D index [17]. Their results were generally not statistically significant, except for Eastern Europe and western Russia. This study also examines NAO-related variability, so a more proper comparison can be made in the next section. Only the BI showed a decrease over the first part of the 21st century for the NH. These decreases were significant in the entire $\mathrm{NH}$, as well as for the Atlantic and Continental Region, a result consistent with the study of [38] who used the 2D BI of [17], while little change in BI was found for the Pacific Region. Seasonally, statistically significant decreases in BI were found during the fall and winter, but BI showed in increase during the summer (but this change was not significant).

The increases across all regions and seasons were surprising; however, as shown above, several studies have examined blocking over more limited regions and seasons and shown similar strong increases. Again, [28,49] and [50] showed similar increases within the boreal warm season in recent decades. On the other hand, [6,15] and [18] showed or highlighted blocking increases over the Atlantic for the winter, and [6] showed that blocking occurrences over the same period covered by [1] were 
associated with a significant minimum. Additionally, [7] showed an increase in blocking since 2000, as shown by the three blocking indexes including the index used here. Taken together, these studies provide supporting evidence that the increases in NH blocking occurrence is likely real. However, whether this change is due to interdecadal variability or climate change will be examined below. Lastly, the mean number of simultaneous blocking days (defined as the number of days with two or more blocking events occurring concurrently in any NH sectors) per year since [1] is 104.2 days, or $28.5 \%$ of the year. This represents a large increase over [1], which found the number of simultaneous blocking days to be approximately $8.7 \%$ of the year.

Examining the NH block genesis regions (Figure 1) shows that since the study of [1] there are more blocking events occurring across the $\mathrm{NH}$ in general with the exception of the region surrounding North America. A comparison of the distributions from the late 20th century (Figure 1a) to that of the early 21st century (Figure 1b) using the chi-square test for similarity [48] shows that the distributions are similar at the $90 \%$ confidence level. The locations of the Pacific Region $\left(180^{\circ}-120^{\circ} \mathrm{W}\right)$ and Atlantic-Eurasia maxima $\left(30^{\circ} \mathrm{W}-60^{\circ} \mathrm{E}\right)$ are located similarly during both time frames. Finally, as found in [1], there is a statistically significant correlation (at the $99 \%$ confidence level) between block duration and BI since 1998.
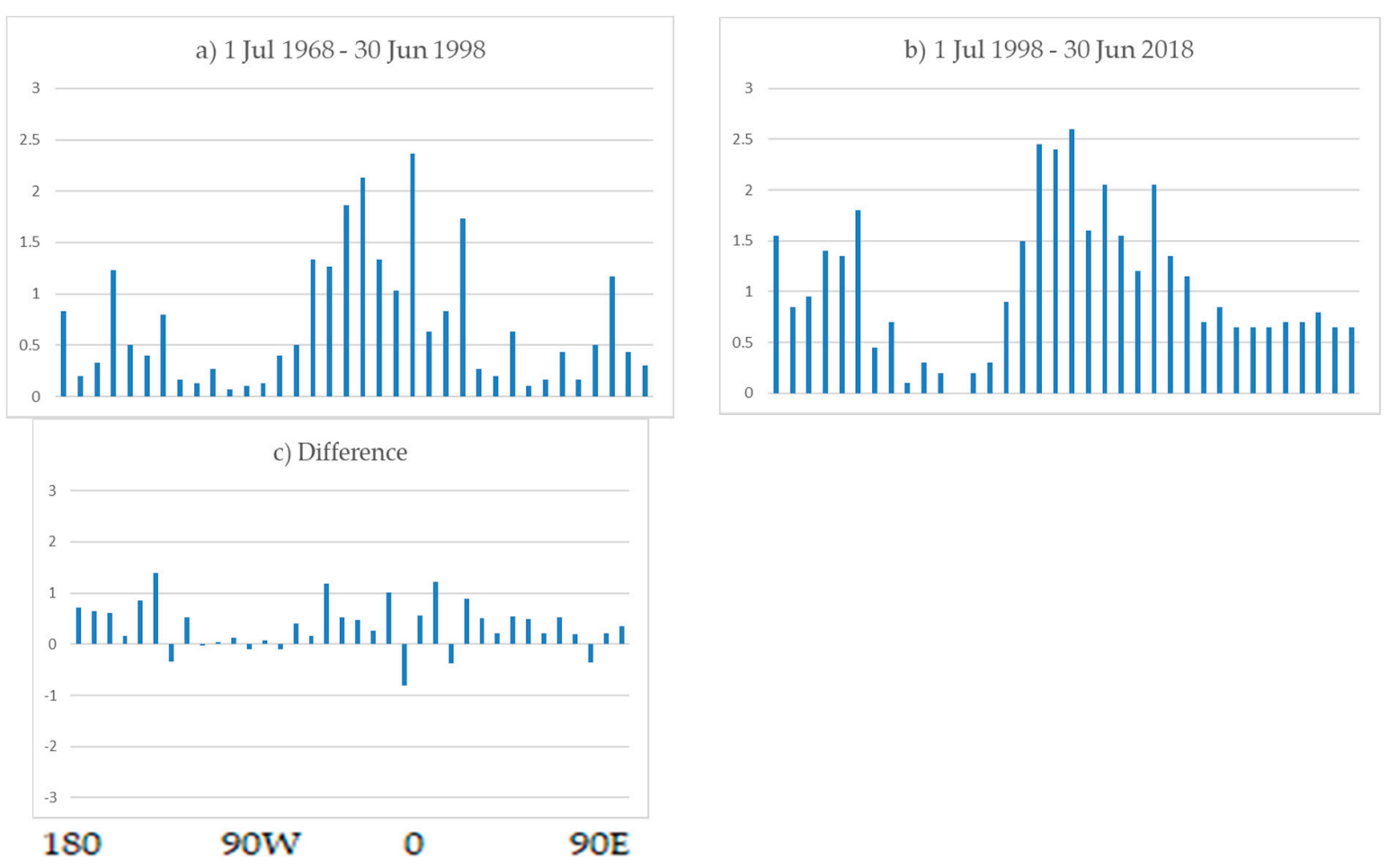

Figure 1. The number of block onsets per year versus longitude where the left-hand side begins with $180^{\circ}$ longitude for the (a) [1] study, (b) the current study period, and (c) the difference between (b) and (a).

\subsection{The Southern Hemisphere}

Examining blocking in the SH (Table 3) and comparing with the work of [1] shows similar increases in block occurrence to the $\mathrm{NH}$ above. The weakest increases in the number of events and blocking days occurred within the Pacific Region, and unlike the NH this region is the predominant blocking region accounting for about three-quarters of all events when counting the number of blocking events and blocking days. The increases are consistent with [12] although their study included more events (durations greater than three days) for only the austral winter. Their increases were found using linear trends over their entire 53-year period, and those may not reflect the strong increases shown since the late 1990s minimum [1]. This issue will be examined in Section 4. 
For SH block durations, there was a significant increase in Pacific Region events and overall (Table 3). The seasonal durations were significantly greater in all seasons with the exception of the austral summer. The SH duration increases overall were weaker than their $\mathrm{NH}$ counterparts, but still some of these statistically significant at the $95 \%$ confidence level. Only BI showed no significant change in the SH overall. However, Pacific Region blocking was significantly stronger since 2000, while blocking in the other two sectors was significantly weaker. BI showed statistically significant increases during the austral summer, but significant decreases during the spring. Lastly, the number of simultaneous blocking days per year since [1] in the SH is 16.4 days per year $(4.5 \%)$, which is higher than the $1.5 \%$ found by [1]. This result is similar to the NH increase in simultaneous blocking days and the result will be discussed more below.

Table 3. As in Table 2, except for the SH.

\begin{tabular}{|c|c|c|c|c|}
\hline Region & Occurrence & Duration & Days & Intensity \\
\hline Atlantic (ATL) & $1.6 /+77.8 *$ & $6.5 /+9.6$ & $10.7 /+92.4$ * & $2.68 /-13.0$ * \\
\hline Pacific (PAC) & $12.0 /+51.9 *$ & $8.3 /+11.8$ * & $99.2 /+67.6$ * & $2.89 /+3.9$ \\
\hline Indian (IND) & $2.8 /+211.1$ * & $7.3 /-3.3$ & $20.3 /+198.5$ * & $2.67 /-4.7$ \\
\hline Total & $16.5 /+69.3$ * & $7.9 /+8.5$ * & $130.3 /+83.3$ * & $2.84 /+0.7$ \\
\hline Season & Occurrence & Duration & Days & Intensity \\
\hline Summer (Su) & $2.1 /+75.0 *$ & $6.7 /+6.1$ & $14.2 /+82.1 *$ & $2.86 /+10.0$ * \\
\hline Fall (F) & $5.2 /+48.6$ * & $8.0 /+5.8$ & $41.7 /+59.2 *$ & $3.04 /+3.1$ \\
\hline Winter (W) & $5.7 /+78.1 *$ & $8.2 /+7.6$ & $46.5 /+89.0 *$ & $2.85 /+0.4$ \\
\hline Spring (Sp) & $3.5 /+92.8$ * & $7.8 /+15.7 *$ & $27.2 /+111.3 *$ & $2.46 /-6.5 *$ \\
\hline
\end{tabular}

Like the $\mathrm{NH}, \mathrm{SH}$ block genesis regions did not change appreciably in the early 21st century versus those of the late 20th century (Figure 2). The distribution for block genesis in the late 20th century (Figure 1a) compared with the block genesis regions for the early 21st century were similar at the $99 \%$ confidence level, a result stronger than that for the NH. In concert with Table 3, there were increases in blocking across the entire $\mathrm{SH}$, and the main genesis region for the late 20th century was roughly $140^{\circ} \mathrm{E}$ to $120^{\circ} \mathrm{W}$, while for the early 21 st century the corresponding region is located about $10^{\circ}$ west of that for the late 20th century. Finally, [1] found no correlation between block duration and BI, however since 2000 , the correlation was 0.11 , which is significant at the $95 \%$ confidence level.

\section{Discussion: Interannual and Interdecadal Variability}

In this section, the change in ENSO variability as well as PDO, NAO, and AMO variability is examined. ENSO variability in blocking is well established in general, and changes in this variability associated with longer-term cycles will be the focus here. In order to accomplish the latter, the data from [1] and the post-[1] years will be reanalyzed by stratifying the blocking years using the PDO epochs defined in Section 2.2. Coincidentally, a change in phase of the PDO and AMO occurred near the end of the epoch from [1], thus it might be reasonable to assume that the recent increases in blocking are related to either the change in the phase of the PDO or AMO, or to a warmer climate. It is conceded here that the period of study is not long enough to have a clear view of multidecadal variations of blocking or whether the long-term trends are due to natural variations or anthropogenic forcing. The work of [15] suggests that both these issues are still outstanding challenges in studies of blocking climatologies. Nonetheless, the results here agree with more limited of regional studies such as [6] or [7]. Additionally, the increases in blocking found here and in the many references cited above, as of yet conflict with the suggested future occurrence of blocking by models, which generally project decreases in blocking for the end of the 21st century [15]. 


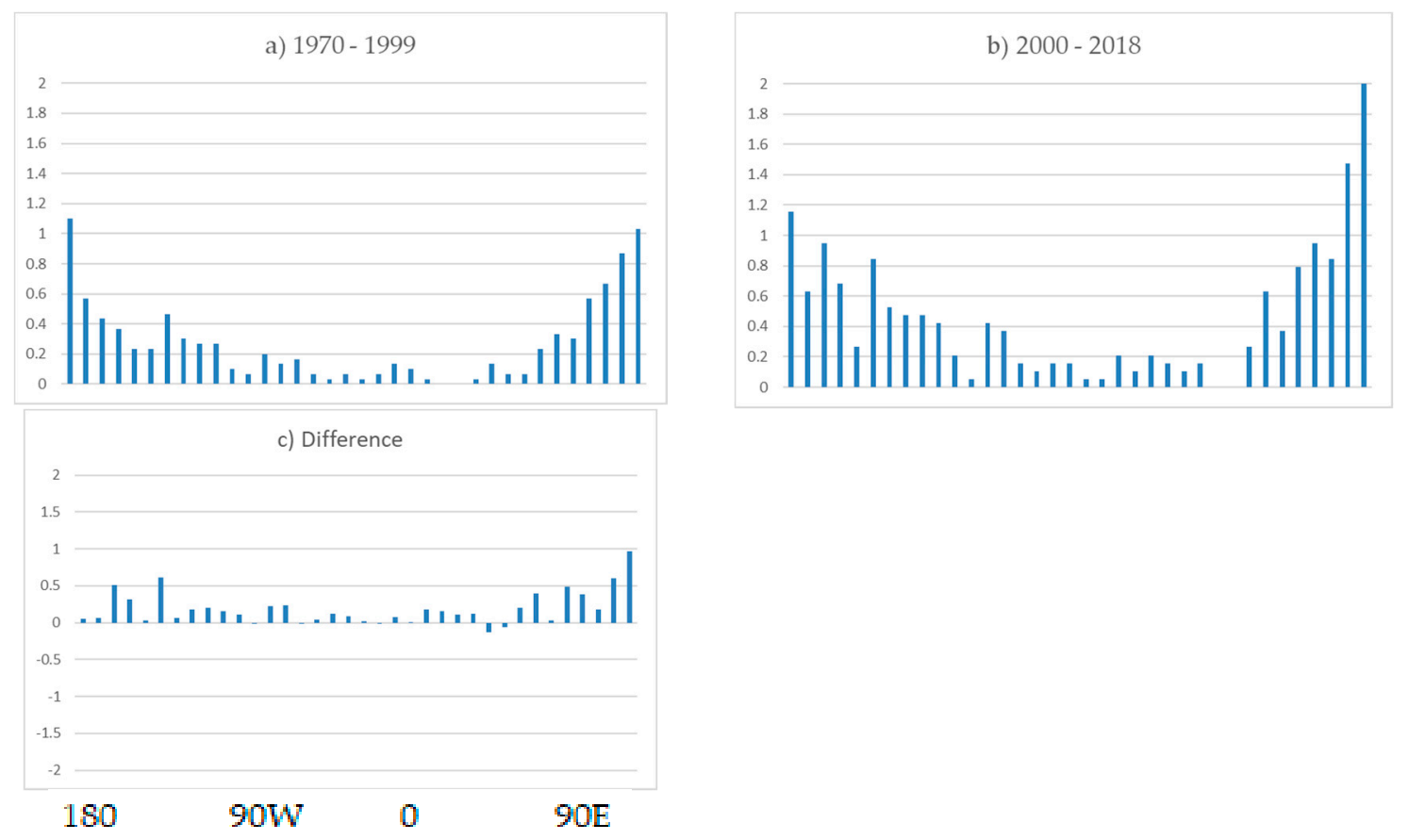

Figure 2. As in Figure 1, except for the SH.

\subsection{The Northern Hemisphere}

Figure 3 shows the trends for the $\mathrm{NH}$ and $\mathrm{SH}$ blocking overall. The linear trend line shows a statistically significant upward trend in block occurrences when tested using analysis of variance (ANOVA) techniques (F-test) [48]. Each of the subregions shows a similar trend. This differs from [1] who showed a slight downward trend in the $\mathrm{NH}$ and a statistically significant downward trend for the SH for the late 20th century. In [1], the period of analysis began during a negative PDO epoch and ended near the termination of the late 20th century PDO epoch. Thus, the trends shown in [1] may be a function of the starting and ending points in their analysis. A comparison of the results found here to those shown in [1] would demonstrate that this sensitivity in trends could also be a function of region, season, or characteristic. This can be shown by examining Tables 2 and 3 that show differing trends for variables like duration and intensity or comparing these results to [38]. Also, for block occurrence, a comparison of these results to those of [1] (their Figures 4 and 5) show very different trends regionally in both hemispheres over different analysis periods.

If there is longer term decadal variability present, this would be revealed through the longer dataset. Thus, a quadratic regression line is fitted to Figure 3. Both the NH and SH suggest the downward trend for block occurrences in the late 20th century found by [1] and the sharper upward trend found in the earlier 21st century suggested in Section 3. The quadratic curves resemble the longer-term variability suggested by [6] and [7]. Also, the late 1980s to mid-1990s minimum in the blocking time series coincide with the positive phases of the PDO (1977-1998) and NAO (1973-1995), and the negative phase of the AMO (1968-1995), which showed considerable overlap. While this analysis alone cannot confirm interdecadal variability in the occurrence of blocking, a spectral analysis of the detrended time series shows significant interdecadal variability in both hemispheres (Figure 4). Thus, the spectral analysis supports the assertion that an interdecadal signal in both hemispheres is present. However, further analysis is needed for positive attribution. 

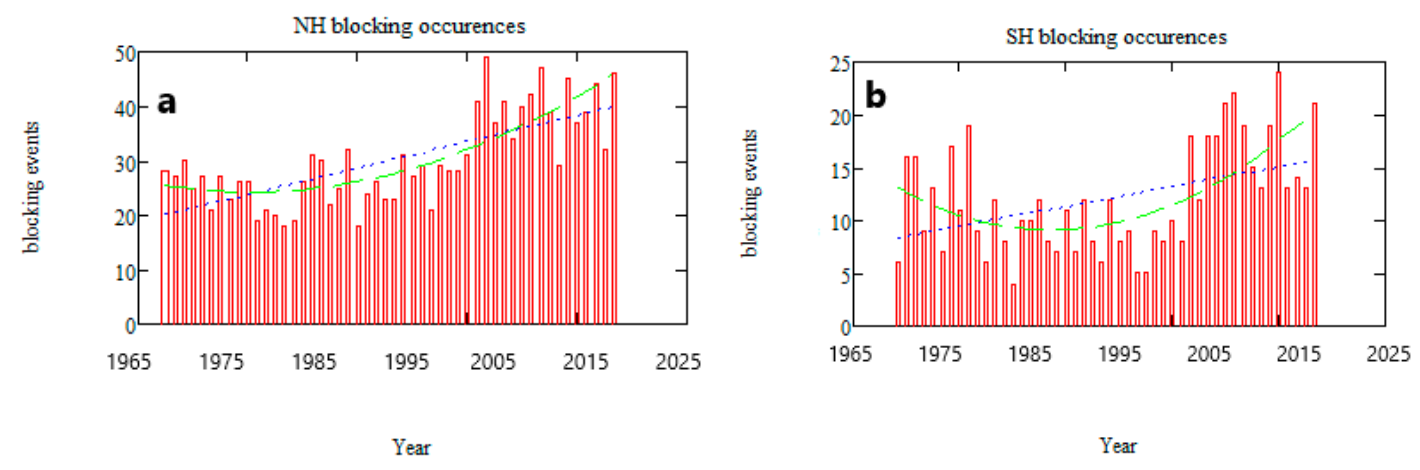

Figure 3. The occurrence of blocking for (a) the $\mathrm{NH}$, and (b) the $\mathrm{SH}$ with time. The blue dashed line is a linear trend line, while the green dashed line is a quadratic fit.

The results of stratifying the blocking characteristics in order to reveal interannual and interdecadal in NH blocking events can be elicited from Table 4 and Appendix A. The results here are tested for statistically significant differences between the phases of interdecadal modes (positive versus negative-Table 4 and Appendix A) as well as the interannual variability within each phase (Table 4). The results show that the total number of blocking events, days, and durations were higher for the negative phase of both the PDO and NAO but the positive phase of the AMO (significant at the $90 \%$ confidence level or higher). However, for all three oscillations, the BI indicated weaker events (negative PDO, NAO, positive AMO) these were significant (at the $90 \%$ confidence level) for the NAO only. These results are similar to the occurrence and intensity of blocking following the [1] study in Section 3 above.

Additionally, during the positive PDO (Table 4), the ENSO variability matched that of [1], which implied that blocking events during La Niña years were associated with more blocking events and days and which were slightly stronger. These ENSO related differences were significant at the $90 \%$ confidence level for each characteristic except for intensity. However, during the positive NAO phase (Appendix A) there were more blocking events and days during El Niño years, but which were stronger during La Niña years. Here, only the blocking days and intensity showed significant differences at the $90 \%$ confidence level. For the negative AMO (Appendix A), there were more events during La Nina years and these events were stronger, but neither of these variables were different at standard levels of significance. Note also that all 10 of the most persistent events occurred since the study of [1] (Appendix B), while only one of these blocking events were among the top 10 strongest (Appendix C).

Table 4. Character of NH blocking events per year as a function of ENSO and PDO. The number of years in each category is shown in parenthesis. Bold numbers are statistical significance at the $90 \%$ confidence level and an $\left({ }^{*}\right)$ represents statistical significance at the $95 \%$ confidence level.

\begin{tabular}{cccccc}
\hline + PDO & Occurrence & Duration & Days & Intensity & \% Simult. \\
\hline El Niño (6) & $\mathbf{2 3 . 5}$ & 8.1 & $\mathbf{1 9 0 . 4}$ & 3.06 & 7.6 \\
Neutral (15) & 24.4 & 8.2 & 200.1 & 3.26 & 8.9 \\
La Niña (2) & $\mathbf{3 0 . 5}$ & 8.3 & $\mathbf{2 5 3 . 3}$ & 3.11 & 12.7 \\
Total (23) & $\mathbf{2 4 . 7}$ & $\mathbf{8 . 2}$ & $\mathbf{2 0 2 . 5}$ & 3.20 & $\mathbf{8 . 9}$ \\
- PDO & Occurrence & Duration & Days & Intensity & \% Simult. \\
El Niño (7) & $\mathbf{3 7 . 0}$ & 9.6 & $\mathbf{3 5 5 . 2}$ & 3.13 & 24.4 \\
Neutral (11) & 36.4 & 9.9 & 361.5 & 3.01 & 28.2 \\
La Niña (9) & $\mathbf{3 1 . 3}$ & 8.6 & $\mathbf{2 7 0 . 1}$ & 3.12 & 16.8 \\
Total (27) & $\mathbf{3 4 . 9}$ & $\mathbf{9 . 4}$ & $\mathbf{3 2 9 . 0}$ & 3.08 & $\mathbf{2 3 . 4}$ \\
\hline
\end{tabular}

Then during the negative PDO phase (Table 4) the ENSO variability was the opposite of the positive phase in that El Niño years were associated with the greater number of blocking events, days, and slightly stronger. These ENSO differences were also significant at the $90 \%$ confidence level or higher. This demonstrates that the character of NH blocking ENSO variability changed with a change 
in the phase of the PDO. The work of [5] showed little ENSO related variability for blocking in their study. However, if the overall set of years (50) for $\mathrm{NH}$ blocking character were examined, there would be little ENSO variability overall as in [5]. Nonetheless, the change in in character of blocking as associated with ENSO variability with the phase of the PDO would be consistent with similar behavior of other phenomenon such as tropical cyclone character [51]. For the negative phase of the NAO (Appendix A), the ENSO variability was similar to that of the positive NAO except that there was no longer any variability in BI. There was no ENSO related variability of significance to report for the positive AMO.

In order to determine which regions or seasons were associated with a greater degree of interannual or interdecadal variability, the blocking data were stratified by region (Table 5 and Appendix A) and season (Table 6 and Appendix A). Examining Table 5, it is clear that during the positive PDO, the relatively less frequent occurrence of blocking during El Niño years was largely due to fewer events in the Continental and Pacific Regions, while Atlantic Region events were less persistent. Pacific region blocking events were much weaker during El Niño years as well. The seasonal differences (Table 6) were reflected by fewer El Niño year blocking events occurring during the all boreal seasons except the fall, while the differences in BI were accounted for by weaker events during El Niño fall and winter.

During the positive NAO (Appendix A), the greater frequency of El Niño year NH blocking is largely reflected by the more frequent occurrences and persistence of Atlantic and Continental Region events, but blocking was more persistent in the Pacific as well. Also, blocking was more frequent during the boreal summer and fall, and more persistent in all seasons except summer. The Atlantic and Pacific Region events were weaker during these years, as well as during the fall and winter (Appendix A). For the negative AMO, the stronger and larger number of blocking events were due mainly to the differences for these variables in the Atlantic and Pacific Regions, and during the winter and spring.
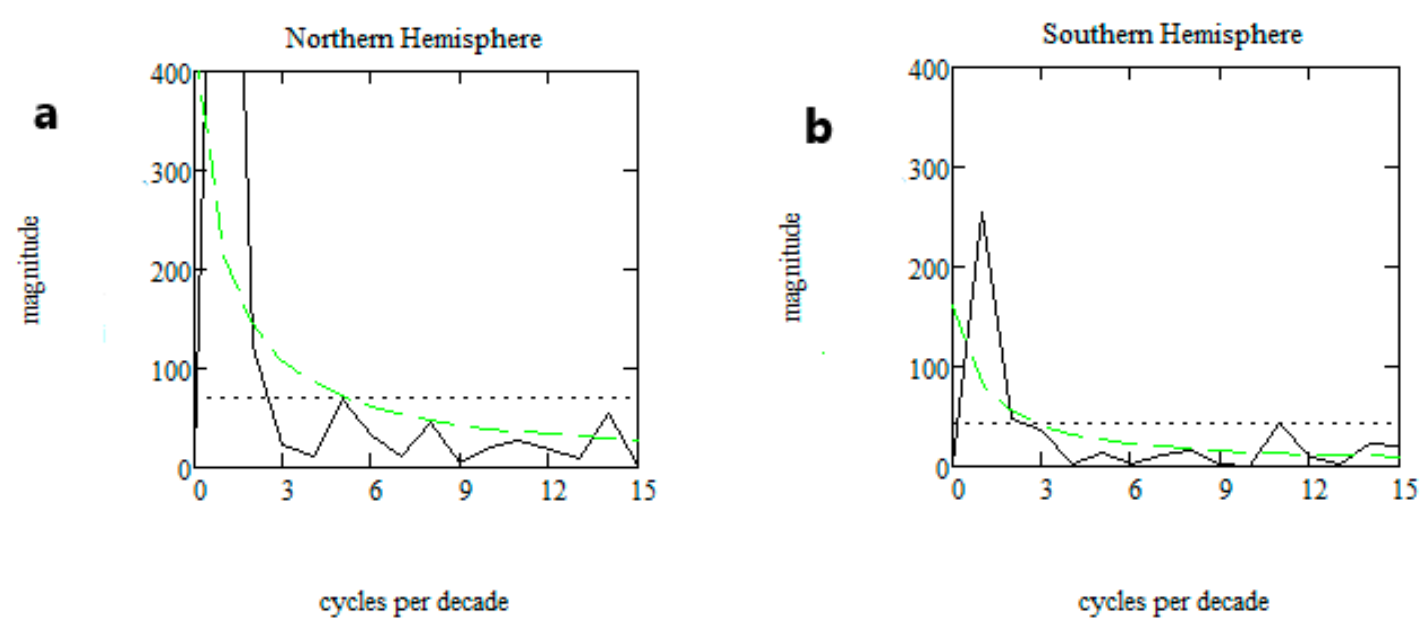

Figure 4. A spectral analysis of the time series for (a) NH (left) and (b) SH (right) block occurrences. The dotted line is the $95 \%$ confidence level assuming a white noise spectrum, while the green dashed line assumes a red noise spectrum (see [52]). The abscissa is cycles per decade and the ordinate is spectral power.

During the negative phase of the PDO, ENSO variability was spread more uniformly throughout each region of the NH (Table 5) and each boreal season (Table 6). Given that there was little BI variability overall (Table 4), the regional and seasonal BIs varied more erratically. For the negative phase of the NAO (Appendix A), the greater occurrence of blocking during El Niño years was most notable in the Atlantic and Pacific Regions and during all seasons expect the spring. The BI showed similar variability in the Atlantic and Pacific as well, but only during the fall did the variability match that of the total BI variability. 
Lastly, a comparison of NAO related variability found here for the Atlantic and Continental region for the cold season was compared to the results of [38] (Tables A1 and A2). Our results showed that the occurrence and duration of blocking was higher in the Atlantic Region, while BI showed weaker events. The duration results are different from [38], but cover all seasons here. A comparison of winter results only showed a similar difference in duration, but the results cover all regions here. It was not immediately clear why the duration in our study showed an increase compared to the decrease in [38].

Table 5. Character of NH blocking events per year by region (ATL/PAC/CON) as a function of ENSO and PDO. The number of years in each category is shown in parenthesis. The values highlighted in red show variability similar to the overall values in Table 4.

\begin{tabular}{ccccc}
\hline+ PDO & Occurrence & Duration & Days & Intensity \\
\hline El Niño (6) & $12.8 / 5.8 / 4.8$ & $8.4 / 7.7 / 8.1$ & $107.3 / 45.1 / 39.1$ & $3.43 / 2.55 / 2.65$ \\
Neutral (15) & $12.1 / 6.3 / 6.1$ & $8.4 / 7.8 / 8.2$ & $101.0 / 48.9 / 49.9$ & $3.46 / 3.44 / 2.67$ \\
La Niña (2) & $12.5 / 9.5 / 8.5$ & $9.4 / 7.2 / 7.9$ & $117.8 / 68.2 / 67.5$ & $3.25 / 3.41 / 2.57$ \\
Total (23) & $12.3 / 6.4 / 6.0$ & $8.5 / 7.7 / 8.2$ & $104.1 / 49.6 / 48.6$ & $3.43 / 3.23 / 2.65$ \\
- PDO & Occurrence & Duration & Days & Intensity \\
El Niño (7) & $16.3 / 12.3 / 8.4$ & $10.5 / 8.7 / 9.2$ & $170.3 / 106.6 / 77.1$ & $3.33 / 3.16 / 2.64$ \\
Neutral (11) & $16.0 / 11.1 / 9.3$ & $10.5 / 9.7 / 9.3$ & $167.4 / 107.8 / 86.0$ & $3.17 / 3.17 / 2.47$ \\
La Niña (9) & $14.6 / 8.1 / 7.7$ & $8.9 / 8.6 / 8.0$ & $129.3 / 78.1 / 61.4$ & $3.37 / 3.17 / 2.37$ \\
Total (27) & $15.6 / 10.7 / 8.5$ & $10.0 / 9.1 / 8.9$ & $155.5 / 97.6 / 75.5$ & $3.27 / 3.19 / 2.52$ \\
\hline
\end{tabular}

Table 6. As in Table 5, except the NH blocking events were separated by season (Su/F/W/Sp).

\begin{tabular}{ccccc}
\hline+ PDO & Occurrence & Duration & Days & Intensity \\
\hline El Niño (6) & $4.5 / 5.5 / 5.7 / 7.8$ & $7.4 / 7.8 / 10.2 / 7.4$ & $33.3 / 42.9 / 57.7 / 57.7$ & $2.16 / 3.63 / 3.71 / 2.52$ \\
Neutral (15) & $5.1 / 4.9 / 7.5 / 6.9$ & $7.1 / 8.6 / 8.4 / 8.5$ & $36.5 / 41.8 / 62.9 / 58.7$ & $2.17 / 3.62 / 4.09 / 2.77$ \\
La Niña (2) & $5.0 / 5.5 / 7.5 / 12.5$ & $8.7 / 8.3 / 9.7 / 7.3$ & $43.5 / 45.8 / 72.8 / 91.5$ & $1.94 / 3.83 / 4.16 / 2.48$ \\
Total (23) & $5.0 / 5.1 / 7.0 / 7.7$ & $7.3 / 8.3 / 8.9 / 8.0$ & $36.3 / 42.4 / 62.4 / 61.3$ & $2.14 / 3.65 / 4.01 / 2.68$ \\
- PDO & Occurrence & Duration & Days & Intensity \\
El Niño (7) & $8.9 / 8.3 / 10.1 / 9.7$ & $8.9 / 9.2 / 10.0 / 10.1$ & $78.4 / 76.1 / 101.8 / 97.8$ & $2.36 / 3.58 / 3.70 / 2.80$ \\
Neutral (11) & $7.8 / 8.5 / 9.3 / 10.8$ & $10.6 / 9.9 / 9.8 / 9.6$ & $82.7 / 83.4 / 91.2 / 104.1$ & $2.31 / 3.37 / 3.79 / 2.59$ \\
La Niña (9) & $6.2 / 7.2 / 9.1 / 9.3$ & $9.5 / 8.2 / 8.7 / 8.3$ & $59.0 / 59.3 / 78.9 / 77.3$ & $2.24 / 3.27 / 3.45 / 2.56$ \\
Total (27) & $7.5 / 7.9 / 9.5 / 10.0$ & $9.8 / 9.2 / 9.5 / 9.3$ & $73.7 / 73.5 / 89.8 / 93.5$ & $2.31 / 3.52 / 3.77 / 2.67$ \\
\hline
\end{tabular}

\subsection{The Southern Hemisphere}

In the $\mathrm{SH}$, as in the $\mathrm{NH}$, the occurrence and persistence blocking was greater during the negative PDO (Table 7) and the positive AMO phases (not shown), and these results are significant at the $90 \%$ confidence level or higher using a Z-score test of the means. However, for both of these epochs, there was no difference in the BI. The mean number of SH blocking events during the positive and negative phases of the AMO was 14 and 10, respectively. In this part of the world, however, the ENSO variability did not change across the phase of the PDO or the AMO. During both PDO epochs, blocking occurred more often, was more persistent and more intense during El Niño and Neutral years as compared to La Niña years. The ENSO variability within each interdecadal mode was also significant for blocking occurrence at the $95 \%$ confidence level. The greater frequency and persistence of block occurrences in the SH compares favorably with the results of [12], in spite of the different blocking criterion used. The study of [12] did not examine interdecadal variability in SH blocking, only the interannual variability. The ENSO related variability during each phase of the AMO was similar to that of the PDO (not shown). There was no statistically significant NAO related variability found in any SH blocking characteristic (not shown). Finally, seven of the longest lived (Appendix B) and six of the strongest (Appendix C) blocking events have occurred since 2000.

In the SH, the Pacific Region and the austral fall and winter (Table 3) are by far the dominant region and seasons for the occurrence of blocking. It is therefore prudent to stratify the characteristics of blocking by region (Table 8) and season (Table 9). Thus, it is expected that the Pacific Region and fall 
and winter ENSO and PDO variability would be close to that of the overall variability found in Table 7, which is the case here. Additionally, the Indian Ocean Region blocking events also reflect the overall interannual and interdecadal variability.

Table 7. As in Table 4, except for SH blocking events.

\begin{tabular}{cccccc}
\hline+ PDO & Occurrence & Duration & Days & Intensity & \% Simult. \\
\hline El Niño (5) & $\mathbf{9 . 0}^{*}$ & 7.0 & $\mathbf{6 3 . 2} *$ & 3.02 & 1.7 \\
Neutral (15) & $\mathbf{9 . 5}^{*}$ & 7.1 & $\mathbf{6 7 . 3} *$ & 2.76 & 1.4 \\
La Niña (2) & $\mathbf{6 . 0}^{*}$ & 6.7 & $\mathbf{4 0 . 3}$ & 2.74 & 0.0 \\
Total (22) & $\mathbf{9 . 0}^{*}$ & $\mathbf{7 . 1}$ & $\mathbf{6 3 . 9} *$ & 2.83 & $\mathbf{1 . 3}$ \\
- PDO & Occurrence & Duration & Days & Intensity & \% Simult. \\
El Niño (8) & $\mathbf{1 6 . 5}^{*}$ & 8.2 & $\mathbf{1 3 4 . 7}$ & 2.89 & 4.6 \\
Neutral (10) & $\mathbf{1 5 . 7}_{\text {La Niña (9) }}^{\mathbf{1 3 . 0}^{*}}$ & 7.9 & $\mathbf{1 2 3 . 3}$ & 2.83 & 4.1 \\
Total (27) & $\mathbf{1 5 . 0}^{*}$ & 7.6 & $\mathbf{9 8 . 4}$ & 2.71 & 2.8 \\
\hline
\end{tabular}

Table 8. As in Table 5, except for SH blocking events.

\begin{tabular}{ccccc}
\hline+ PDO & Occurrence & Duration & Days & Intensity \\
\hline El Niño (5) & $0.4 / 7.8 / 0.8$ & $6.8 / 7.1 / 6.6$ & $2.7 / 55.6 / 5.3$ & $2.19 / 3.04 / 2.95$ \\
Neutral (15) & $1.1 / 7.7 / 0.7$ & $6.0 / 7.2 / 7.0$ & $6.4 / 55.4 / 5.2$ & $2.91 / 2.72 / 2.98$ \\
La Niña (2) & $0.5 / 5.5 / 0.0$ & $8.0 / 6.6 / 0.0$ & $4.0 / 36.2 / 0.0$ & $1.84 / 3.10 / \mathrm{NA}$ \\
Total (22) & $0.9 / 7.5 / 0.7$ & $6.2 / 7.2 / 6.9$ & $5.3 / 53.7 / 4.7$ & $2.76 / 2.66 / 2.98$ \\
- PDO & Occurrence & Duration & Days & Intensity \\
El Niño (8) & $1.6 / 11.6 / 3.1$ & $6.1 / 8.5 / 8.2$ & $9.9 / 99.1 / 25.7$ & $3.26 / 2.94 / 2.79$ \\
Neutral (10) & $1.6 / 11.9 / 2.2$ & $6.2 / 8.3 / 6.8$ & $10.0 / 98.9 / 14.9$ & $2.68 / 2.90 / 2.51$ \\
La Niña (9) & $1.2 / 9.8 / 2.0$ & $6.7 / 7.8 / 7.3$ & $8.2 / 75.9 / 14.6$ & $2.84 / 2.70 / 2.62$ \\
Total (27) & $1.5 / 11.0 / 2.4$ & $6.3 / 8.2 / 7.5$ & $9.3 / 90.6 / 18.0$ & $2.91 / 2.86 / 2.66$ \\
\hline
\end{tabular}

Table 9. As in Table 6, except for SH blocking events.

\begin{tabular}{ccccc}
\hline + PDO & Occurrence & Duration & Days & Intensity \\
\hline El Niño (5) & $0.8 / 3.4 / 3.6 / 1.2$ & $6.0 / 7.0 / 7.6 / 6.0$ & $4.8 / 23.8 / 27.4 / 7.2$ & $2.28 / 3.23 / 3.11 / 2.48$ \\
Neutral (15) & $0.9 / 3.4 / 3.3 / 1.9$ & $6.0 / 7.3 / 7.3 / 6.5$ & $5.2 / 24.9 / 24.2 / 12.2$ & $2.34 / 2.85 / 2.80 / 2.74$ \\
La Niña (2) & $2.5 / 1.0 / 1.0 / 1.5$ & $5.9 / 8.5 / 6.8 / 6.8$ & $14.8 / 8.5 / 6.8 / 10.2$ & $2.71 / 3.55 / 3.93 / 2.26$ \\
Total (22) & $1.0 / 3.2 / 3.2 / 1.7$ & $6.0 / 7.3 / 7.3 / 6.5$ & $6.0 / 23.1 / 23.4 / 10.9$ & $2.33 / 2.77 / 2.83 / 2.54$ \\
- PDO & Occurrence & Duration & Days & Intensity \\
El Niño (8) & $2.0 / 5.1 / 5.5 / 3.9$ & $6.7 / 8.6 / 8.7 / 8.0$ & $13.3 / 44.2 / 48.0 / 30.9$ & $3.00 / 3.09 / 2.82 / 2.56$ \\
Neutral (10) & $1.9 / 5.5 / 5.8 / 2.5$ & $6.9 / 7.9 / 8.6 / 6.9$ & $13.1 / 43.2 / 49.6 / 22.4$ & $2.62 / 2.97 / 2.91 / 2.43$ \\
La Niña (9) & $2.2 / 4.1 / 3.7 / 3.0$ & $6.8 / 8.0 / 6.9 / 8.5$ & $15.2 / 32.8 / 25.4 / 21.2$ & $2.97 / 2.89 / 2.59 / 2.43$ \\
Total (27) & $2.0 / 4.9 / 5.0 / 3.1$ & $6.8 / 8.1 / 8.4 / 7.8$ & $13.8 / 40.0 / 41.5 / 23.7$ & $2.86 / 2.98 / 2.74 / 2.48$ \\
\hline
\end{tabular}

The proportion of East Pacific blocking versus West Pacific blocking was examined in [12] and [53]. They [12] show that West Pacific blocking is more frequent than East Pacific blocking and both showed weak upward trends. Central Pacific blocking was decreasing in [12]. Then [53] defined the West Pacific (East Pacific) blocking regions as $130^{\circ} \mathrm{E}$ to $160^{\circ} \mathrm{W}\left(160^{\circ} \mathrm{W}\right.$ to $\left.60^{\circ} \mathrm{W}\right)$. Their [53] preliminary investigation showed that approximately $36 \%$ of Pacific Region blocking occurred in the East Pacific, and that this did not change appreciably with time of with respect to the PDO, and this result agrees with [12]. However, there was a reversal in the proportion of East Pacific blocking occurrences when compared to those of the west Pacific Region. During the positive PDO phase there were a larger fraction of the East Pacific Region blocking during La Niña and Neutral years, while the opposite was true during the negative PDO epoch (La Niña years showed the smallest fraction of East Pacific blocking). Also, a preliminary investigation shows the duration of East Pacific blocking events have a similar duration, but that the intensity of East Pacific blocking events is significantly greater. Additionally, the Pacific South American pattern (PSA-e.g., [54-58]), which is analogous to 
the PNA in the NH, can impact the occurrence of blocking and is modulated by ENSO. PSA-1 (PSA-2) would favor blocking in the west (central and east) Pacific, showing positive height anomalies in the midlatitudes with negative height anomalies equatorward. Then, for example, [58] demonstrates that there is significant variability in the PSA as related to ENSO (see their Figures 5 and 6) and this agrees with our results here.

The work of [1] speculated that the greater occurrence of simultaneous blocking events in the $\mathrm{NH}$ versus those in the $\mathrm{SH}$ was due to the greater number of occurrence of blocking since previous work [59] demonstrated that the occurrence of blocking was caused local synoptic processes rather than hemisphere-wide planetary-scale processes. Also, [11] suggested that SH blocking was more the result of the superposition of favorable synoptic and planetary-scale dynamics, while the interactions were greater and mutually synergistic in the $\mathrm{NH}$.

The results here are similar since the fewest number of blocking events occurred during the $\mathrm{SH}$ positive PDO epoch as well as the fewest number of simultaneous days. The opposite was true in that the largest number of simultaneous blocking days occurred during the NH negative PDO epoch, which showed the largest number of blocking occurrences. The correlation coefficient between the number of simultaneous blocking days and the number of events was 0.89 for the entire 50 -year $\mathrm{NH}$ time series, and 0.77 for the 49 -year SH time series. Both results are statistically significant at the $99 \%$ confidence level, and support the idea that the occurrence of more blocking events increases the likelihood of simultaneously occurring events.

\section{Summary and Conclusions}

This study examined the occurrence of blocking over the entire globe since the study of [1] (into the early 21st century up to the end of 2018), and included such characteristics as occurrence, duration, blocking days, block intensity (BI), and the number of simultaneous blocking days. The dataset used was the four times daily NCEP/NCAR reanalyses of $500 \mathrm{hPa}$ heights and the archive of blocking events are found at [28]. In order to facilitate a comparison of this study with [1], the blocking criterion used, as well as the region and seasonal definitions, were used here. Then, the long-term trends as well as interannual and interdecadal variability were examined, and the new results are discussed below.

This study showed statistically significant increases in block occurrences and days since the end of the 20th century in both hemispheres. In the NH, the block duration increased but not significantly, but there was a statistically significant decrease in BI. In the $\mathrm{SH}$, the block duration was significantly larger and there was little change in the BI. In the $\mathrm{NH}$, the increases found here were consistent with the results of others $[6,7,29,38,49]$ who examined 'partial' climatologies of certain regions during certain seasons. These results were also consistent with the results of blocking climatologies using 2D indexes, especially for the Atlantic Region $[18,38]$. Differences in duration were noted only when comparing with the Atlantic Region winter results of [38]. The work of [6] implied that the period 1970-1999 showed a relative minimum in Atlantic Region boreal winter blocking, and [43] discusses work that shows Atlantic Region blocking on the increase in the early 21st century. Then [12] showed that $\mathrm{SH}$ block occurrences have increased across most of the $\mathrm{SH}$, but they used a less strict definition of blocking. Thus, there is strong evidence to support the results here. In the SH, the increases in Pacific Region blocking were not as strong as their NH counterparts.

Separating the occurrence of blocking by phase of ENSO and PDO, NAO, or AMO showed that the in the $\mathrm{NH}$, the positive PDO epoch was associated with interannual variability in the occurrence, duration, and BI similar to that found in [1] as expected. During the negative PDO epoch, which included recent years, the interannual variability in block occurrence was opposite that of the positive PDO epoch, with the exception of BI, which showed little ENSO related variability. The ENSO related variability in block occurrence was found primarily in the Pacific and Continental Regions during both phases of the PDO, but during all boreal seasons. The exceptions were that there was no clear signal in the BI, and Atlantic Region blocking followed the total interannual variability in the negative PDO phase. 
With respect to the NAO, there were more blocking events during the negative phase across the $\mathrm{NH}$, but the ENSO related interannual variability was similar in each phase in that there were more blocking events during El Niño years. La Niña blocking was stronger during the positive phase of the NAO, which is a similar result to that of the positive phase of the PDO. NAO-related interannual variability was found primarily in the Atlantic Region as expected, but in the Continental Region during the positive NAO and in the Pacific Region during the negative NAO. Additionally, the results here could not differentiate between the North Atlantic versus Europe for the NAO as in [38] or [39]. Both of the [38] subregions fall within the Atlantic Region as defined here (see [38] for more details).

During the positive AMO, there were more blocking events of stronger duration but weaker than those events during the negative phase of the AMO. This result is similar to comparing the results of Section 3 to those of [1]. This should not be a surprising result since the period of study for [1] was dominated by the negative AMO and the early 21st century by the positive AMO.

In the $\mathrm{SH}$, blocking was more abundant and more persistent, but of similar intensity, during the negative phase of the PDO and the positive AMO. However, the interannual variability was the same for each phase of the PDO and AMO, in spite of the increases in occurrence, duration, and days. The interannual variability during AMO phases was statistically significant as it was for the PDO. There was no statistically significant $\mathrm{NAO}$ related variability in the $\mathrm{SH}$. In the $\mathrm{SH}$, the interdecadal and interannual variability was most apparent in the Pacific Region and during the austral fall and winter. Within the Pacific Region, a preliminary study shows that the relative occurrence of East Pacific blocking was greater in La Niña and Neutral years than during El Niño years during the positive PDO epoch. The opposite occurred during the negative PDO phase. Finally, an examination of the occurrence of simultaneous blocking events demonstrated that the greater frequency in blocking occurrence correlated highly with the occurrence of multiple blocking events, supporting the conjecture of [1].

Author Contributions: Conceptualization of the work is credited to A.R.L. and I.I.M. Methodology was contributed by all authors; Software, A.R.L.; Formal Analysis, all authors; Investigation, all authors; Resources, A.R.L.; Data Curation, A.R.L.; Writing-Original Draft Preparation, A.R.L.; Writing-Review \& Editing, all authors.

Funding: This research received no external funding.

Acknowledgments: The authors would like to acknowledge the anonymous reviewers for their time and effort in examining this manuscript. Their comments made this manuscript a stronger contribution. This work was partially supported by the Russian Foundation of Basic Research (RFBR-I.I.M. and A.V.T.) (grant numbers 17-05-01097 and 17-29-05098) and the National Science Foundation (NSF-A.R.L. and T.E) (grant number IIA1355406). Any opinions, findings, and conclusions or recommendations expressed in this material are those of the authors and do not necessarily reflect the views of the NSF.

Conflicts of Interest: The authors declare no conflict of interest.

\section{Appendix A}

Table A1. NH blocking events per year by region (ATL/PAC/CON/Total) as a function of ENSO and NAO. The number of years in each category is shown in parentheses. Here statistical significance is indicated with $\left.{ }^{*}{ }^{* *}\right)$ at the $90 \%(95 \%)$ confidence level.

\begin{tabular}{ccccc}
\hline + NAO & Occurrence & Duration & Days & Intensity \\
\hline El Niño (8) & $14.9 / 7.6 / 6.0 / \mathbf{2 8 . 5}$ & $9.2 / 8.6 / 8.4 / 8.9$ & $137.1 / 65.3 / 50.3 / \mathbf{2 5 0 . 8}$ & $3.42 / 2.93 / 2.71 / 3.17^{*}$ \\
Neutral (19) & $13.0 / 7.6 / 7.3 / \mathbf{2 7 . 8}$ & $8.8 / 9.1 / 8.7 / 8.9$ & $114.4 / 68.8 / 63.3 / \mathbf{2 4 6 . 7}$ & $3.43 / 3.48 / 2.66 / 3.26$ \\
La Niña (4) & $13.3 / 8.3 / 4.3 / \mathbf{2 5 . 6}$ & $8.2 / 7.0 / 7.9 / 7.8$ & $108.3 / 58.0 / 33.7 / 200.1$ & $3.60 / 3.18 / 2.70 / 3.33$ \\
Total (31) & $\mathbf{1 3 . 5 / 7 . 7 / 6 . 5 / 2 7 . 7 * *}$ & $\mathbf{8 . 8 / 8 . 7 / 8 . 6 / 8 . 7}$ & $\mathbf{1 1 9 . 5 / 6 6 . 5 / 5 6 . 1 / 2 4 2 . 3} * *$ & $\mathbf{3 . 4 5 / 3 . 3 1 / 2 . 6 8 / 3 . 2 4}$ \\
- NAO & Occurrence & Duration & Days & Intensity \\
El Niño (5) & $14.4 / 12.0 / 8.0 / 34.4$ & $10.3 / 8.2 / 9.3 / 9.3$ & $147.7 / 98.8 / 74.4 / 321.0$ & $3.28 / 3.06 / 2.56 / 3.05$ \\
Neutral (8) & $16.5 / 10.9 / 8.4 / 35.8$ & $10.5 / 8.7 / 8.9 / 9.6$ & $173.9 / 94.7 / 74.7 / 343.9$ & $3.11 / 3.00 / 2.39 / 2.92$ \\
La Niña (6) & $13.6 / 8.8 / 9.5 / 31.8$ & $9.3 / 8.7 / 7.9 / 8.8$ & $126.1 / 76.7 / 74.6 / 279.2$ & $3.21 / 3.21 / 2.39 / 3.00$ \\
Total (19) & $\mathbf{1 5 . 0 / 1 0 . 5 / 8 . 6 / 3 4 . 2 * *}$ & $\mathbf{1 0 . 1 / 8 . 6 / 8 . 6 / 9 . 3}$ & $\mathbf{1 5 1 . 9 / 9 0 . 2 / 7 4 . 6 / 3 1 7 . 4 * *}$ & $\mathbf{3 . 1 8 / 3 . 0 8 / 2 . 4 3 / 2 . 9 8 *}$ \\
\hline
\end{tabular}


Table A2. As in Table A1, except for NH blocking events per year by season (Su/F/W/Sp).

\begin{tabular}{ccccc}
\hline+ NAO & Occurrence & Duration & Days & Intensity \\
\hline El Niño (8) & $6.3 / 6.3 / 6.7 / 9.3$ & $8.4 / 8.7 / 10.6 / 8.1$ & $52.2 / 54.4 / 71.4 / 74.9$ & $2.43 / 3.47 / 3.87 / 2.76$ \\
Neutral (19) & $5.5 / 5.7 / 8.4 / 8.2$ & $8.0 / 9.7 / 8.9 / 8.8$ & $43.8 / 55.5 / 74.9 / 72.5$ & $2.27 / 3.55 / 4.06 / 2.78$ \\
La Niña (4) & $4.3 / 4.5 / 8.3 / 8.8$ & $8.9 / 7.2 / 8.5 / 6.8$ & $37.8 / 32.4 / 70.4 / 59.5$ & $2.17 / 3.88 / 4.23 / 2.70$ \\
Total (31) & $5.5 / 5.7 / 8.0 / 8.5$ & $8.2 / 9.1 / 9.2 / 8.4$ & $45.2 / 52.2 / 73.4 / 71.4$ & $2.31 / 3.55 / 4.03 / 2.77$ \\
- NAO & Occurrence & Duration & Days & Intensity \\
El Niño (5) & $7.8 / 8.2 / 10.2 / 8.2$ & $8.5 / 8.7 / 9.5 / 10.5$ & $66.2 / 71.1 / 97.4 / 86.2$ & $2.15 / 3.76 / 3.51 / 2.62$ \\
Neutral (8) & $8.6 / 8.6 / 8.3 / 10.3$ & $10.8 / 8.6 / 9.7 / 9.5$ & $93.0 / 73.9 / 79.8 / 97.1$ & $2.27 / 3.36 / 3.67 / 2.58$ \\
La Niña (6) & $6.5 / 7.7 / 8.7 / 9.9$ & $9.0 / 8.6 / 8.9 / 8.7$ & $58.3 / 65.9 / 76.8 / 85.1$ & $2.28 / 3.55 / 3.57 / 2.52$ \\
Total (19) & $7.7 / 8.2 / 8.9 / 9.6$ & $9.7 / 8.6 / 9.4 / 9.4$ & $75.0 / 71.6 / 83.5 / 90.4$ & $2.25 / 3.52 / 3.60 / 2.57$ \\
\hline
\end{tabular}

Table A3. As in Table A1, except as a function of ENSO and AMO.

\begin{tabular}{|c|c|c|c|c|}
\hline + AMO & Occurrence & Duration & Days & Intensity \\
\hline El Niño (6) & $16.5 / 12.3 / 9.2 / 38.0$ & $10.1 / 9.3 / 8.9 / 9.5$ & 166.6/114.4/81.9/361.0 & $3.28 / 3.10 / 2.58 / 3.07$ \\
\hline Neutral (12) & $15.5 / 11.0 / 9.2 / 35.7$ & $10.5 / 9.6 / 9.3 / 9.9$ & $162.8 / 105.6 / 85.6 / 353.4$ & $3.22 / 3.20 / 2.48 / 3.05$ \\
\hline La Niña (5) & 14.8/11.0/11.1/37.0 & $10.1 / 8.9 / 8.2 / 9.2$ & 149.5/97.9/91.2/340.4 & $3.17 / 3.36 / 2.47 / 3.03$ \\
\hline Total (23) & $15.6 / 11.3 / 9.6 / 36.6^{* *}$ & $10.3 / 9.4 / 8.9 / 9.6$ * & $160.7 / 106.2 / 85.4 / 351.4^{* *}$ & 3.23/3.21/2.50/3.05 \\
\hline - AMO & Occurrence & Duration & Days & Intensity \\
\hline El Niño (7) & $13.1 / 6.7 / 4.7 / 24.6$ & $9.1 / 7.0 / 7.7 / 8.5$ & $119.2 / 46.9 / 36.2 / 209.1$ & $3.48 / 2.77 / 3.10 / 3.17$ \\
\hline Neutral (14) & $12.2 / 6.0 / 5.9 / 24.1$ & $8.2 / 7.7 / 8.0 / 8.1$ & $100.0 / 46.2 / 47.2 / 194.2$ & $3.41 / 3.43 / 2.68 / 3.23$ \\
\hline La Niña (6) & $13.7 / 7.7 / 5.0 / 26.2$ & 7.9/7.6/7.6/7.8 & $108.3 / 58.5 / 38.0 / 204.4$ & $3.55 / 3.18 / 2.58 / 3.28$ \\
\hline Total (27) & $12.7 / 6.6 / 5.4 / 24.7 * *$ & 8.4/7.4/7.9/8.1 * & $106.7 / 48.8 / 42.7 / 200.1 * *$ & $3.44 / 3.20 / 2.75 / 3.23$ \\
\hline
\end{tabular}

Table A4. As in Table A2, except as a function of ENSO and AMO.

\begin{tabular}{ccccc}
\hline + AMO & Occurrence & Duration & Days & Intensity \\
\hline El Niño (6) & $8.7 / 8.7 / 10.2 / 10.5$ & $8.7 / 9.0 / 10.1 / 10.1$ & $75.7 / 79.1 / 103.0 / 106.1$ & $2.31 / 3.45 / 3.64 / 2.77$ \\
Neutral (12) & $7.5 / 8.2 / 9.3 / 10.7$ & $10.5 / 9.9 / 9.7 / 9.7$ & $78.8 / 81.2 / 90.2 / 103.8$ & $2.32 / 3.40 / 3.86 / 2.58$ \\
La Niña (5) & $7.0 / 8.0 / 10.2 / 11.6$ & $10.4 / 8.9 / 8.8 / 8.9$ & $72.8 / 71.2 / 89.8 / 103.2$ & $2.30 / 3.65 / 3.61 / 2.62$ \\
Total (23) & $7.7 / 8.3 / 9.8 / 10.8$ & $9.9 / 9.5 / 9.6 / 9.6$ & $76.2 / 78.9 / 94.1 / 104.7$ & $2.31 / 3.46 / 3.73 / 2.64$ \\
- AMO & Occurrence & Duration & Days & Intensity \\
El Niño (7) & $5.3 / 5.6 / 6.3 / 7.4$ & $7.7 / 8.2 / 10.5 / 7.5$ & $40.8 / 45.9 / 66.2 / 55.5$ & $2.40 / 3.83 / 3.66 / 2.61$ \\
Neutral (14) & $5.2 / 4.9 / 7.3 / 6.8$ & $7.0 / 8.4 / 8.4 / 8.3$ & $36.4 / 41.2 / 61.3 / 56.4$ & $2.13 / 3.60 / 4.03 / 2.82$ \\
La Niña (6) & $5.0 / 5.3 / 7.8 / 8.2$ & $8.2 / 7.4 / 8.8 / 7.0$ & $41.0 / 39.2 / 68.6 / 57.4$ & $2.07 / 3.88 / 4.14 / 2.69$ \\
Total (27) & $5.2 / 5.1 / 7.1 / 7.3$ & $7.4 / 8.1 / 9.0 / 7.8$ & $38.5 / 41.3 / 63.9 / 56.9$ & $2.19 / 3.72 / 3.96 / 2.74$ \\
\hline
\end{tabular}

\section{Appendix B}

Table A5. The top 10 longest lived blocking events in the Northern Hemisphere (top) and Southern Hemisphere (bottom) from 1968 to the present.

\begin{tabular}{cclc}
\hline Rank & Event & Days & Region \\
\hline 1. & June 2003 & 35.0 & Co \\
2. & December 2016 & 33.5 & AR \\
3. & December 2010 & 33.0 & AR \\
& May 2013 & 33.0 & PR \\
& July 2013 & 33.0 & PR \\
6. & December 2002 & 32.5 & AR \\
7. & July 2003 & 32.0 & Co \\
8. & February 2005 & 31.5 & AR \\
9. & February 2005 & 31.0 & AR \\
10. & May 2014 & 29.5 & Co \\
Rank & Event & Days & Region \\
1. & July 2015 & 28.0 & IN \\
2. & July 1976 & 26.0 & PR \\
3. & May 2016 & 25.0 & PR \\
\hline
\end{tabular}


Table A5. Cont.

\begin{tabular}{cccc}
\hline Rank & Event & Days & Region \\
\hline 4. & June 2005 & 22.5 & PR \\
5. & May 2008 & 21.0 & PR \\
6. & May 1973 & 20.5 & IN \\
7. & August 2004 & 20.5 & PR \\
8. & June 1981 & 20.0 & PR \\
9. & June 2012 & 20.0 & PR \\
10. & May 2009 & 19.5 & PR \\
& October 2010 & 19.5 & PR \\
\hline
\end{tabular}

\section{Appendix C}

Table A6. The top 10 strongest (BI) blocking events in the Northern Hemisphere (top) and Southern Hemisphere (bottom) from 1968 to the present.

\begin{tabular}{cccc}
\hline Rank & Event & BI & Region \\
\hline 1. & February 1991 & 6.42 & PR \\
2. & March 1996 & 6.40 & PR \\
3. & November 1997 & 6.31 & AR \\
4. & March 1989 & 6.20 & PR \\
5. & January 1985 & 6.17 & PR \\
6. & December 1996 & 6.16 & PR \\
7. & January 1979 & 6.09 & PR \\
8. & February 1975 & 6.08 & AR \\
& December 1983 & 6.08 & PR \\
10. & January 2008 & 5.99 & AR \\
Rank & Event & BI & Region \\
1. & July 2006 & 5.46 & PR \\
2. & October 1995 & 5.40 & AR \\
3. & May 1991 & 5.30 & PR \\
4. & May 2016 & 5.08 & PR \\
5. & September 1996 & 5.00 & PR \\
6. & July 2016 & 4.85 & PR \\
7. & June 1995 & 4.83 & PR \\
8. & June 2005 & 4.80 & PR \\
9. & May 2000 & 4.71 & PR \\
10. & June 2007 & 4.68 & PR \\
\hline
\end{tabular}

\section{References}

1. Wiedenmann, J.M.; Lupo, A.R.; Mokhov, I.I.; Tikhonova, E.A. The climatology of blocking anticyclones for the Northern and Southern Hemisphere: Block intensity as a diagnostic. J. Clim. 2002, 15, 3459-3474. [CrossRef]

2. Pelly, J.L.; Hoskins, B.J. A new perspective on blocking. J. Atmos. Sci. 2003, 60, 743-755. [CrossRef]

3. Schwierz, C.; Croci-Maspoli, M.; Davies, H. Perspicacious indicators of atmospheric blocking. Geophys. Res. Lett. 2004, 31. [CrossRef]

4. Croci-Maspoli, M.; Schweirz, C.; Davies, H. Atmospheric blocking: Space-time links to the NAO and PNA. Clim. Dyn. 2007, 29, 713-725. [CrossRef]

5. Barriopedro, D.; Garcia-Herrera, R.; Lupo, A.R.; Hernandez, E. A climatology of Northern Hemisphere Blocking. J. Clim. 2006, 19, 1042-1063. [CrossRef]

6. Häkkinen, S.; Rhines, P.B.; Worthen, D.L. Atmospheric Blocking and Atlantic Multidecadal Ocean Variability. Science 2011, 334, 655-659. [CrossRef]

7. Mokhov, I.I.; Akperov, M.G.; Prokofyeva, M.A.; Timazhev, A.V.; Lupo, A.R.; Le Treut, H. Blockings in the Northern Hemisphere and Euro-Atlantic region: Estimates of changes from reanalyses data and model simulations. Doklady 2012, 449, 430-433. [CrossRef] 
8. Luo, D.; Xiao, Y.; Yao, Y.; Dai, A.; Simmonds, I.; Franzke, C. Impact of Ural Blocking on Winter Warm Arctic-Cold Eurasian Anomalies, Part I: Blocking-Induced Amplification. J. Clim. 2016, 29, 3925-3947. [CrossRef]

9. Luo, D.; Xiao, Y.; Diao, Y.; Dai, A.; Franzke, C.; Simmonds, I. Impact of Ural Blocking on Winter Warm Arctic-Cold Eurasian Anomalies, Part II: The link to the North Atlantic Oscillation. J. Clim. 2016, 29, 3949-3971. [CrossRef]

10. Diao, Y.; Li, J.; Luo, D. A New Blocking Index and Its Application: Blocking Action in the Northern Hemisphere. J. Clim. 2006, 19, 4819-4839. [CrossRef]

11. Burkhardt, J.P.; Lupo, A.R. The planetary and synoptic-scale interactions in a Southeast Pacific blocking episode using PV diagnostics. J. Atmos. Sci. 2005, 62, 1901-1916. [CrossRef]

12. Oliveira, F.N.M.; Carvalhoc, L.M.V.; Ambrizzi, T. A new climatology for southern hemisphere blockings in the winter and the combined effect of ENSO and SAM phases. Int. J. Climatol. 2014, 34, 1676-1692. [CrossRef]

13. Renwick, J.A.; Revell, M.J. Blocking over the South Pacific and Rossby wave propagation. Mon. Wea. Rev. 1999, 127, 2233-2247. [CrossRef]

14. Wallace, J.M.; Gutzler, D.S. Teleconnections in the geopotential height field during the Northern Hemisphere winter. Mon. Wea. Rev. 1981, 109, 784-812. [CrossRef]

15. Woollings, T.; Barriopedro Cepero, D.; Methven, J.; Son, S.-W.; Harvey, B.; Martius, O.; Sillmann, J.; Lupo, A.R.; Seneviratne, S. Blocking and it's response to climate change. Current Clim. Chang. Rep. 2018, 4, 287-300. [CrossRef]

16. Barnes, E.A.; Polvani, L.M. CMIP5 projections of Arctic amplification, of the North American/North Atlantic circulation, and of their relationship. J. Clim. 2015, 28, 5254-5271. [CrossRef]

17. Scherrer, S.C.; Croci-Maspoli, M.; Schwierz, C.; Appenzeller, C. Two-dimensional indices of atmospheric blocking and their statistical relationship with winter climate patterns in the Euro-Atlantic Region. Int. J. Climatol. 2006, 262, 233-249. [CrossRef]

18. Davini, P.; Cagnazzo, C.; Gualdi, S.; Navarra, A. Bidimensional duagnostics, variability, and trends of Northern Hemisphere blocking. J. Clim. 2012, 25, 6496-6509. [CrossRef]

19. Rimbu, N.; Stefan, S.; Necula, C. The variability of winter high temperature extremes in Romania and its relationship with large-scale atmospheric circulation. Theor. App. Clim. 2014, 121, 121-130. [CrossRef]

20. Mokhov, I.I. Action as an integral characteristic of climatic structures: Estimates for atmospheric blocking. Dokl. Ear. Sci. 2006, 409, 925-928. [CrossRef]

21. Lupo, A.R.; Oglesby, R.J.; Mokhov, I.I. Climatological features of blocking anticyclones: A study of Northern Hemisphere CCM1 model blocking events in present-day and double $\mathrm{CO}_{2}$ concentration atmospheres. Clim. Dyn. 1997, 13, 181-195. [CrossRef]

22. Sillmann, J.; Croci-Maspoli, M. Present and future atmospheric blocking and its impact on European and extreme climate. Geophys Res Lett. 2009, 36, L10702. [CrossRef]

23. Sciafe, A.A.; Copsey, D.; Gordon, C.; Harris, C.; Hinton, T.; Keeley, S.; O’Neill, A.; Roberts, M.; Williams, K. Improved Atlantic Winter Blocking in a Climate Model. Geophys. Res. Lett. 2010, 38, L23703.

24. Mokhov, I.I.; Timazhev, A.V.; Lupo, A.R. Changes in atmospheric blocking characteristics within Euro-Atlantic region and Northern Hemisphere as a whole in the 21st century from model simulations using RCP anthropogenic scenarios. Glob Planet. Chng. 2014, 122, 265-270. [CrossRef]

25. Jensen, A.D.; Lupo, A.R.; Mokhov, I.I.; Akperov, M.G.; Sun, F. The dynamic character of Northern Hemisphere flow regimes in a near term climate change projection. Atmosphere 2018, 9, 27. [CrossRef]

26. Kalnay, E.; Kanamitsu, M.; Kistler, R.; Collins, W.; Deaven, D.; Gandin, L.; Iredell, M.; Saha, S.; White, G.; Woollen, J.; et al. The NCEP/NCAR 40-year reanalysis project. Bull. Am. Meteorol. Soc. 1996, 77, 437-471. [CrossRef]

27. NCEP/NCAR Reanalyses Project. Available online: http://www.esrl.noaa.gov/psd/data/reanalysis/ reanalysis.shtml (accessed on 11 May 2017).

28. University of Missouri Blocking Archive. Available online: http://weather.missouri.edu/gcc (accessed on 26 June 2017).

29. Newberry, R.G.; Lupo, A.R.; Jensen, A.D.; Rodriges-Zalipynis, R.A. An analysis of the spring-to-summer transition in the West Central Plains for application to long range forecasting. Atmos. Clim. Sci. 2016, 6, 375-393. [CrossRef] 
30. Center for Ocean and Atmosphere Prediction Studies. Available online: http://www.coaps.fsu.edu (accessed on 11 May 2017).

31. Hanley, D.E.; Bourassa, M.A.; O’Brien, J.J.; Smith, S.R.; Spade, E.R. A Quantitative Evaluation of ENSO Indices. J. Clim. 2003, 16, 1249-1258. [CrossRef]

32. Bove, M.C.; Elsner, J.B.; Landsea, C.W.; Niu, X.; O’Brien, J.J. Effects of El Niño on U.S. Landfalling Hurricanes, Revisited. Bull. Am. Meteorol. Soc. 1998, 79, 2477-2482. [CrossRef]

33. Hu, Z.Z.; Huang, B. Interferential Impact of ENSO and PDO on Dry and Wet Conditions in the U.S. Great Plains. J. Clim. 2009, 19, 5500-5518. [CrossRef]

34. Birk, K.; Lupo, A.R.; Guinan, P.E.; Barbieri, C.E. The interannual variability of midwestern temperatures and precipitation as related to the ENSO and PDO. Atmofera 2010, 23, 95-128.

35. Mantua, N.J.; Hare, S.R.; Zhang, Y.; Wallace, J.M.; Francis, R.C. A Pacific Interdecadal Climate Oscillation with Impacts on Salmon Production. Bull. Am. Meteorol. Soc. 1997, 78, 1069-1079. [CrossRef]

36. Minobe, S. A 50-70-Year Climatic Oscillation over the North Pacific and North America. Geophys. Res. Lett. 1997, 24, 683-686. [CrossRef]

37. Feldstein, S.B. The dynamics of NAO teleconnection pattern growth and decay. Q. J. R. Meteorol. Soc. 2003, 129, 901-924. [CrossRef]

38. Luo, D.; Yao, Y.; Dai, A. Decadal Relationship between European Blocking and the North Atlantic Oscillation during 1978-2011. Part I: Atlantic Conditions. J. Atmos. Sci. 2015, 72, 1152-1173. [CrossRef]

39. Luo, D. Decadal Relationship between European Blocking and the North Atlantic Oscillation during 1978-2011. Part II: A Theoretical Model Study. J. Atmos. Sci. 2015, 72, 1174-1199. [CrossRef]

40. da Costa, E.D.; de Verde, A.C. The 7.7-year North Atlantic Oscillation. Q. J. R. Meteorol. Soc. 2002, 128, 797-818. [CrossRef]

41. Mokhov, I.I.; Smirnov, D.A. El Niño-Southern Oscillation drives North Atlantic Oscillation as revealed with non-linear techniques from climatic indicies. Geophys. Res. Lett. 2006, 33, 3708-3711. [CrossRef]

42. Wang, Y.-H.; Magnusdottir, G.; Stern, H.; Tian, X.; Yu, Y. Decadal variability of the NAO: Introducing an augmented NAO index. Geophys. Res. Lett. 2012, 39, L21702.

43. Woollings, T.; Franzke, C.; Hodson, D.L.R.; Dong, B.; Barnes, E.A.; Raible, C.C.; Pinto, J.G. Contrasting interannual and multidecadal NAO variability. Clim. Dyn. 2015, 45, 539. [CrossRef]

44. Climate Prediction Center, monthly NAO Index. Available online: http://www.cpc.ncep.noaa.gov/ products/precip/CWlink/pna/month_nao_index.shtml (accessed on 19 December 2018).

45. Trenberth, K.E.; Shea, D.J. Atlantic hurricanes and natural variability. Geophys. Res. Lett. 2005, 33, L12704. [CrossRef]

46. van Oldenborgh, G.J.; te Raa, L.A.; Dijkstra, H.A.; Philip, S.Y. Frequency- or amplitude-dependent effects of the Atlantic meridional overturning on the tropical Pacific Ocean. Ocean Sci. 2009, 5, 293-301. [CrossRef]

47. Zhang, R.; Delworth, T.L. Impact of Atlantic multidecadal oscillations on India/Sahel rainfall and Atlantic hurricanes. Geophys. Res. Lett. 2009, 33, L17712. [CrossRef]

48. Neter, J.; Wasserman, W.; Whitmore, G.A. Applied Statistics, 3rd ed.; Allyn and Bacon Inc.: Boston, MA, USA, 1988; p. 1066.

49. Lupo, A.R.; Mokhov, I.I.; Chendev, Y.G.; Lebedeva, M.G.; Akperov, M.G.; Hubbart, J.A. Studying summer season drought in western Russia. Adv. Meteorol. 2014, 1-9. [CrossRef]

50. Lebedeva, M.G.; Krymckaya, O.V.; Lupo, A.R.; Chendev, Y.G.; Petin, A.N.; Solovyov, A. Trends in summer season climate for Eastern Europe and Southern Russia in the early 21st century. Adv. Meteorol. 2016, 2016. [CrossRef]

51. Lupo, A.R. Interannual and Interdecadal variability in hurricane activity. In Recent Hurricane Research: Climate, Dynamics, and Societal Impacts; Lupo, A.R., Ed.; Intech Publishers: Vienna, Austria, 2011; p. 616. ISBN 978-953-307-238-8.

52. Wilks, D.S. Statistical Methods in the Atmospheric Sciences, 2nd ed.; Int. Geophys Series number 91; Academic Press: Cambridge, MA, USA, 2006; p. 627.

53. Lupo, A.R.; Garcia, M.; Rojas, K.; Gilles, J. ENSO Related Seasonal Range Prediction Over South America. In Proceedings of the 2nd International Electronic Conference on Atmospheric Sciences, Columbia, MO, USA, 16-31 July 2017.

54. Karoly, D.J. Southern Hemisphere circulation features associated with El Niño-Southern Oscillation events. J. Clim. 1989, 2, 1239-1252. [CrossRef] 
55. Mo, K.C.; Paegle, J.N. The Pacific-South American modes and their downstream effects. Int. J. Climatol. 2001, 21, 1211-1229. [CrossRef]

56. Cai, W.; Rensch, P.V.; Cowan, T.; Hendon, H.H. Teleconnection Pathways of ENSO and the IOD and the Mechanisms for Impacts on Australian Rainfall. J. Clim. 2011, 24, 3910-3923. [CrossRef]

57. Yu, J.-Y.; Paek, H.; Saltzman, E.S. The Early 1990s Change in ENSO-PSA-SAM Relationships and Its Impact on Southern Hemisphere Climate. J. Clim. 2015, 28, 9393-9408. [CrossRef]

58. O'Kane, T.J.; Monselesan, D.P.; Risbey, J.S. A Multiscale Reexamination of the Pacific-South American Pattern. Mon. Weather Rev. 2017, 145, 379-402. [CrossRef]

59. Lupo, A.R. A diagnosis of two blocking events that occurred simultaneously in the mid-latitude Northern Hemisphere. Mon. Weather Rev. 1997, 125, 1801-1823. [CrossRef]

(C) 2019 by the authors. Licensee MDPI, Basel, Switzerland. This article is an open access article distributed under the terms and conditions of the Creative Commons Attribution (CC BY) license (http:/ / creativecommons.org/licenses/by/4.0/). 